\title{
Economic Potentials of Oil Palm Production and Machinery Use in UDI, Enugu State, Nigeria
}

\author{
Bello R. S. ${ }^{1, ~}$, Bello M. B. ${ }^{2}$, Essien B. A. ${ }^{3}$, Saidu M. J. ${ }^{4}$ \\ ${ }^{1}$ Department of Agriculture \& Bio-Environmental Engineering, Federal College of Agriculture, Ishiagu, Nigeria \\ ${ }^{2}$ Department of Agricultural Economics and Management, Federal College of Agriculture, Ishiagu, Nigeria \\ ${ }^{3}$ Akanu Ibiam Federal Polytechnic, Unwana, Afikpo, Ebonyi State, Nigeria \\ ${ }^{4}$ Department of Agriculture \& Bio-Environmental Engineering, Federal College of Agriculture, Jalingo, Nigeria
}

\section{Email address:}

segemi2002@gmail.com (Bello R. S.), msjauro2020@gmail.com (Saidu M. J.)

\section{To cite this article:}

Bello R. S., Bello M. B., Essien B. A., Saidu M. J.. Economic Potentials of Oil Palm Production in UDI, Enugu State. Science Journal of Business and Management. Special Issue: Sustainable Entrepreneurial Developments in Agribusiness. Vol. 3, No. 5-1, 2015, pp. 16-20. doi: $10.11648 /$ j.sjbm.s.2015030501.14

\begin{abstract}
The economic potential of oil palm production and machinery-use in Udi Local Government Area Enugu State, Nigeria has been investigated. Questionnaires, personal work and oral interview were used as means of information retrieval. Statistical tool were used in data analysis. Farm holding/ownerships are of three categories; Individual (small holding (68\%)), communal (medium holding (23\%)) and cooperative efforts (large scale holdings $(9 \%)$ ) from social groups and friends reduce economic cost on labour. A larger percentage of the small scale holders $(40 \%)$ inherited the farm while $(5 \%)$ claimed ownership of establishing the farm. About $20 \%$ operate on rental arrangements and $30 \%$ communally owned. The result of the profitability analysis in palm oil processing in the area showed an increased trend in profitability while factors like transport costs, high cost of plantation rentals, and poor extraction processes were most critical to inhabiting profitable palm oil processing in the area.
\end{abstract}

Keywords: Oil Palm, Returns, Production, Processing, Hectare

\section{Introduction}

The oil palm sub-sector of Nigeria agriculture presented itself as a potential productive sector that could be used to diversify the economy after years of neglect. The nonparticipation of Nigeria in oil palm plantation development until the late 2000 and government policy on plantation development are most certainly reasons for Nigeria losing her leading position to Malaysia whose total production are export oriented (Green, 2003). Nigeria oil palm production fell, and by 1999 only $10 \%$ of the total value of our annual exports remains. In the past, the Nigerian government had tried to implement large-scale oil palm plantations, most of which resulted in complete failures. The Cross River State palm projects of the 1960's and the 1990's European Unionfunded "Oil palm belt rural development programme" was abandoned in 1999 and reactivated in 2003 and the local governor's intention to privatize it was announced in 2010 (WRM, 2010).

The World Bank played an important role in the promotion of the oil palm business in Nigeria. According to a recent World Bank document, Nigeria has been "the second largest recipient of World Bank palm oil sector projects, with six projects over the 1975 to 2009 period (WRM, 2010). The palm oil from the eastern region was described as being of the highest quality and the people took pride in the work of their hands. The people were so good at it that the Malaysians like the three wise oriental kings followed the scent of the palm oil to Imo state to learn the fine art of palm oil production. However, with the crude mineral oil boom, laziness and indolence took the place of hard work and dignity of labour.

Agriculture suffered a setback as it was relegated to the back burner. Between 2003 and 2005 Nigeria lost her leading place in palm oil export to Malaysia and Indonesia and regained it temporarily between 2005 and 2008. In 2004, according to reports, Indonesia cultivated oil palm plantations which covered 5.3 hectares of land. These plantations generated 11.4 million metric tons of palm oil with an export value of US\$ 4.43 billion and brought in 
$\$ 42.4$ million to the Indonesian treasury. Of course since then, the value of the product has continued to climb, making it almost competitive to petroleum. Kei et al. (1997) highlighted that the stagnation in the oil palm sector in Nigeria was influenced by the overall agricultural policies that could be classified into three periods visa, namely, the independence (1960-1970), the oil export boom period (1970-1985), the appreciation of the Naira and the reduction of duties on food imports made food imports cheaper than domestic staples (Nwauwa, 2011). These actions created biases against agricultural exports (Forest, 1993). During the sap period (1993-2003) on the positive side there was a rise in output prices, improvement in production efficiency and on an increase, in opportunities for small business enterprises. On the negative side however, it led to increased input prices and a sharp increase in the cost of living relative to nominal income (CBN/NISER, 1992) so, national-level consumption has declined following sap implementation.

Iloeje (2001) ascertained that Nigeria's exports of palm oil rose steadily to a peak of 566,400 tones, valued at over N80million in 2004, but fell very abruptly to a minimum of 164,950 tons worth only N20.6million in 2004. This drop is not surprising since the oil palm producing areas were the most seriously distributed. However, there has been limited recovery and exports at 2004 were values at N27million. The declined palm oil and kernel exports were as a result of increased domestic consumption following population grown and the lower producer prices allowed by marketing boards which had a monopoly of purchase for export. Equally, the producer prices given were little more than half the world market prices and discouraged both planting and harvesting (Hartley, 2003). Also contributory was the ceaseless tapping of local wine from the palm tree which reduced the productivity of the palms, hence producing fruit with thinner pericarp, or husks, lowering the quantity of the oil per hectare with poor quality (Iloeje, 2001). These carelessness also led to low yield of oil. Owing to the rapid increase in the demand of oil palm for consumption as well as raw materials for our local and foreign industries, demand for the commodity has exceeded supply which is held responsible for high products demand in the market.

Nigeria has numerous potentials to increase her production primarily though application of improved processing techniques that meet both growth and sustainability goals (Omoti, 2008; Agboola, 2000). However, most technologies are designed for country; nevertheless, most farmers in developing countries use imported seed materials obtained from research station but without a corresponding application of package which are meant to be used with them. Even where these package are used as instructed, yields are always lower than those obtained in research stations which seeds are bred.

\section{Economic Potentials of Oil Palm}

Palm oil (Elaeis Guineensis, native of West Africa) accounts for 34 percent of the world's annual production of vegetable oill and 63 percent of the global exports of vegetable oils (Ayodele, 2010). It is produced in tropical climates and in 42 countries across the world. Palm fruit from which palm oil is extracted is of immense value. Palm oil has long been recognized and widely used as cooking oil and also became a highly sought after commodity by British traders, for use as industrial lubricant for machinery during the Britain's industrial revolution. Palm oil formed the basis of industrial scale soap production, such as Lever Brothers (Unilever Nig Plc) sunlight soap and the American Palmolive brand.

While many products (Figure 1) emanate from the oil palm trees - palm oils, wood by - products, the focus of this research is on the oil products and their direct by - products. There are 117 characteristics which are used to define and grade palm oil in the international trade market. Dominant among them are the levels of free fatty acid (FFA), followed by dirt, iodine, value, and other contaminants. The minimum requirement for SPO is an FFA of less than 5\% which can be consumed or used in products such as creams or further refined for soaps and bleaches oil which does not meet the quality grades of those characteristics $\mathrm{s}$ qualified as TPO with FFA $>5 \%$ and is mainly used for food consumption.

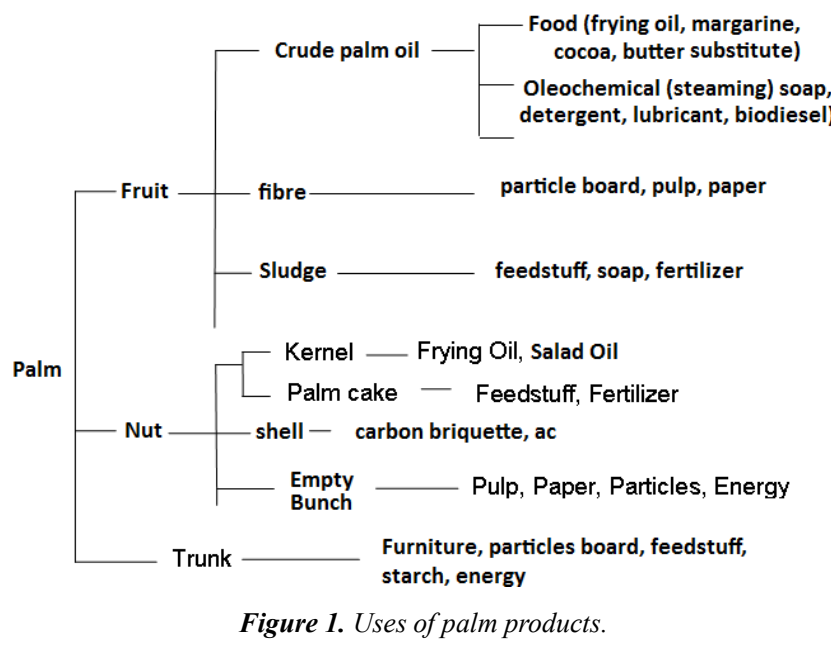

Source: PIND, 2011(Abia State Palm Oil Value Chain Development Project Abia State, Nigeria, 2010)

In developed economies, palm oil is used in the manufacturing of many foodstuffs including many industrial applications as can be seen in Figure 1. In view of potential contributions of oil palm production and processing, it is important to ensure its optimum sustainable development and processing. However, In Nigeria, there has been limited transformation in the usage of the primary or secondary products of oil palm for either food or non-food application.

The significance of the theoretical perspective of the potential of oil palm production lies not only in the identification of different factors affecting production and processing, but also in the determination of the critical areas of possible intervention having fully ascertain the potentials of high productivity and marketability of the products in the 
area.

This paper discussed the economic potentials of oil palm production and processing especially in palm-rich areas as Udi Local Government Area of Enugu state, Nigeria. The study lay emphasis on the seasonal pattern of palm production flow on different production and processing problems encountered by farmers and consumers.

\section{Methodology}

\subsection{Study Area Geography}

The study area, Udi is one of the principal cities in Enugu state; a mainland state in south Eastern Nigeria created in 1991 from the old Anambra State. Udi has an area of $897 \mathrm{~km}^{2}$ and a population of 234, 002 at the 2006 Census. The villages/settlement covered in this research work include Obinagu, Umabi Umagu, Nachi, Oji, Amaokwe, Emegu Amaokwe, Etiti Amaokwe, Uwani Amaokwe and Abia Agbudu.

\subsection{Data Collection and Analysis}

Data were collected through site visits and field interaction with the farmers based on participatory rural appraisals (PRA) (Robson, 1993), and through administered questionnaires (Busha and Harter, 1980) as well as on-the-spot assessment of sampled palm plantation, farms and production centers to consolidate data from questionnaire and interviews. A systemic random sampling approach was used to sample selected palm plantations (individuals and corporate) within the study area (Gomez and Gomez, 1984). Descriptive statistics and budgetary techniques were used to analyze collated data and to determine the gross margin and farm income obtained from oil production and processing respectively.

\subsection{Results and Discussions}

The distribution of the respondents' characteristic shows that oil palm production and processing in the study area is dominated by farmers of the age between $40-59$ years old. $50 \%$ of the palm producers and processors in the area are secondary school certificate (WASCE) holders; higher certificate $(40 \%)$ while $20 \%$ are primary school certificate holders. Farm holding/ownerships are of three categories (PIND, 2011); Individual (small holding (68\%)), communal (medium holding (23\%)) and cooperative efforts (large scale holdings $(9 \%)$ ) from social groups and friends reduce economic cost on labour (Table 1). A larger percentage of the small scale holders (40\%) inherited the farm while $(5 \%)$ claimed ownership of establishing the farm. About $20 \%$ operate on rental arrangements and $30 \%$ communally owned.

Table 1. Costs of production per farm size year per.

\begin{tabular}{lllll}
\hline Holding pattern & Size of Farm (Ha) & Labour Cost /yr x N'000 & Maintenance Cost /yr x N'000 & Transport Cost /yr x N'000 \\
\hline & $1-2$ & 20 & 50 & 8 \\
Small holding (68\%) & $3-4$ & 25 & 80 & 9 \\
& $5-6$ & 30 & 110 & 12 \\
Medium holding (23\%) & $7-8$ & 35 & 130 & 15 \\
Large scale holding (9\%) & $9-10$ & 35 & 150 & 15 \\
\hline
\end{tabular}

Table 1 also shows the cost implications on labour cost, maintenance cost and transport costs per hectare per year of oil palm production within the area. From the table, the cost of hiring labour and maintenance are relatively high owing to labour drift to other sectors of the production economy such as mining and trading. The cost of maintenance is considerably high compare to labour and transport costs.

\section{Project Financing and Machinery Use}

According to farmer's response, $8 \%$ of credit facilities are in bank loan and other organization that give loan, $40 \%$ obtain their capital from personal savings while $10-15 \%$ has no access to loan facilities or any form of inputs and as such farmers were unable to expand their productivity. It difficult to obtain loan and help from firms to boost agricultural production.

Among the palm processing techniques, about $15 \%$ of the processors used modernized hand presses while $75 \%$ still uses the primitive processing equipment for their production (Figure 2).

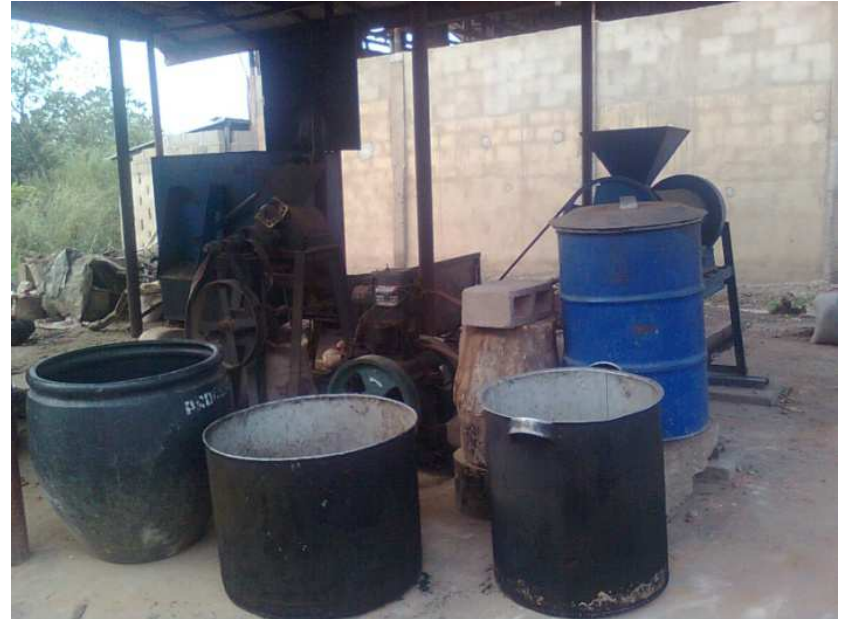

Figure 2. Oil palm processing equipment.

Productivity (yields) on the small holder farms are evidently lower than the large scale holders averages and could be improved with better farm practices which includes; improved weeding methods, use of fertilizers, herbicides, 
and palm pruning. However, these challenges lie in the availability of the inputs, the cost of the inputs, and the knowledge of best practices.

\section{Market Potentials}

Table 2 show the output production per hectare of palm products per year. Range (minimum/maximum) of oil palm produced are between 10-180 drums, and $150-440 \mathrm{~kg}$ of palm kernel (in $\mathrm{kg}$ ) produced per hectare.

Table 2. Palm product output per year and unit cost.

\begin{tabular}{|c|c|c|c|c|}
\hline Farm size & Oil palm (drum) & Cost returns/ yr x N'000 & Palm kernel (Kg) & Cost returns/ yr x N'000 \\
\hline 1-4 hectares & $10-50$ & $40-200$ & $180-200$ & 300 \\
\hline 5-6 hectares & $50-100$ & $200-400$ & $210-280$ & 360 \\
\hline 7-8 hectares & $100-150$ & $400-600$ & $280-320$ & 420 \\
\hline 9-10 hectares & $150-200$ & $600-800$ & $350-440$ & 490 \\
\hline$>10$ hectares & $200-240$ & $800-1000$ & $>600$ & 500 \\
\hline
\end{tabular}

The unit cost of palm oil per drum (20 ltrs) is high relatively $(\mathrm{N} 3,400-\mathrm{N} 4,000)$ in season and more in off season, and available in the open market is as a result of local import from other part of the country.

\section{Labour Cost}

There are three basic labours available to the oil palm production and processing in the study area, are hired labour, family labour and joint efforts of social groups and friends. The data shows that majority of oil palm production and processing use hired labour, the cost using hired labour is, the cost of using hired labour is high and so as the production and yield which is vice versa. This makes it useful to farmers because of increase in yield.

Despite palm oil production being below par, it is a major vocation in many of these communities providing income for many farmers and their dependents; it is also one of the modest revenue sources to some state and local governments. This connotes that an efficient and strong palm oil sector in Nigeria will enable the poor to be part of the solution to poverty challenges through provision of employment and a means of livelihood.

\section{Conclusions}

Following the survey analysis, it is clear that the determinant of net returns showed that costs of palm fruits production are significantly associated with the net returns on production while depreciation of tools and other inputs were negatively affected but significantly related to net return. On the other hand, no significant relationship was found to exist between net return and such variables as processing experience and labor cost. Comparatively, the level of profitability factor based on variables such as transport costs, rentals and extraction were the most critical factors inhabitation profitable palm oil processing in the area.

In order to accelerate net returns in palm oil processing in the area, the government should endeavour to invigorate implementation policy on credit loan facilities accessibility to farmers, accelerate farm-road network integrations in the areas where they do not exist and maintained already existing ones for easy access to raw materials thereby reducing transportation cost in order to boost the revenue of the processors.

\section{References}

[1] Agboola, A.A (2000), "Farming Systems in Nigeria", In fundamentals of Agriculture. Edited by E.A. Aiyelari, M.O. Abata, E.O. Lucas and G.A. Akinboade.

[2] Busha, C. H. and Harter, S. P. (1980) Research methods in librarianship: techniques and interpretation. San Diego: Academic press, 53.

[3] Central Bank of Nigeria CBN (1992). Nigeria Economic and Social Research (NISER) National study (1992). Impact of Structural Adjustment Programme (SAP) on Nigerian Agriculture and Rural Life. Lagos, Nigeria. Page Publishers Services Ltd.

[4] Forest $\mathrm{T}$ (1993). Politics and Economic Development in Nigeria. Boulder: Westview, Inc.

[5] Gomez, K. A and Gomez, A. A (1984) Statistical procedures for Agricultural research. 2nd edition. John Wiley \& Sons, New York.

[6] Green, M.M (2003), Igbo village Affair, 2nd edition Frank Cass, London P.3.

[7] Hartley, C.W.S. (2003) the oil palm. Longman Group ltd London Pp.9 and 11.

[8] Iloeje, N.P (2001), New Geography of Nigeria. New Revised edition. William clowes 1td. Beecdes and London. Pp.81, 82, 83 and 84 .

[9] Jalani, B.S, D. Ariffian, and K.W. chan, (2000). Malaysia's contribution to improving the value and use of palm oil through modern technologies in Burotrop Bultetin N0.19 February 2003 P.25

[10] Kei K, Mywish M, Duncan B (1997). Transformation versus Stagnation in the Oil Palm Industry: A Comparison between Malaysia and Nigeria. Staff Paper 97-5. Department of Agricultural Economics Michigan State University, East Lansing, Michigan 48824 p. 19.

[11] Omoti, U. (2004), problems and prospects of oil palm Development processing and potentials in Nigeria, paper prepared for African Investment and Development Agency conference on attracting private foreign investment into Nigeria's oil palm industry, Kuala Lumpur, December, 2004. 
[12] Nwauwa Linus Onyeka Ezealaji, 2011. Economics of palm oil storage and marketing in Imo State, Nigeria African Journal of Marketing Management Vol. 3(10), pp. 253-260, October 2011 Available online at http://www.academicjournals.org/AJMM ISSN 2141-2421

[13] PIND, 2011 Foundation for Partnership Initiatives in the Niger Delta. A report on Palm Oil Value Chain Analysis in the Niger Delta

[14] Robson, (1993) Real world research a resources for social scientist and practitioners researchers. Oxford: black well. pg. 228.
[15] Thompson Ayodele, 2010. African Case Study: Palm Oil and Economic Development in Nigeria and Ghana; Recommendations for the World Bank's 2010 Palm Oil Strategy

[16] WRM, 2010. World Rainforest Movement. Oil palm in Nigeria: shifting from smallholders and women to mass production WRM's bulletin $\mathrm{N}^{\mathrm{o}}$; 161 December 2010 http://oilpalminafrica.wordpress.com/2010/08/06/oil-palm-innigeria/ 